\title{
Evaluation of hybrid silica sols for stable microporous membranes using high-throughput screening
}

\author{
R. Kreiter • M. D. A. Rietkerk - H. L. Castricum • \\ H. M. van Veen $\cdot$ J. E. ten Elshof $\cdot$ J. F. Vente
}

Received: 15 February 2010/Accepted: 27 March 2010/Published online: 27 April 2010

(C) The Author(s) 2010. This article is published with open access at Springerlink.com

\begin{abstract}
Microporous membranes are a promising option for energy-efficient molecular separations. Longterm hydrothermal stability of the membrane material is of prime importance for several industrial processes. Here, a short overview of silica-based membrane materials and their hydrothermal stability is presented. Following this, the development of a series of organic-inorganic hybrid silica sols is described, based on $\alpha, \omega$-bis(triethoxysilyl)precursors with bridging methane, ethane, propane, and benzene groups. High-throughput screening was used to scan a range of sol parameters, followed by membrane preparation from the most promising sols. These organicinorganic hybrid silica $\left(\mathrm{HybSi}^{\circledR}\right)$ membranes were used in dewatering of lower alcohols by pervaporation. Separation factors up to 200 were found for ethanol/water mixtures, and up to 23 for methanol/water mixtures. Modest permselectivity values for hydrogen over nitrogen were found, ranging up to 20.7 for the shortest bridging group. It was concluded that the length of the organic bridge has a clear effect on the pore size distribution and the selectivity of the membrane.
\end{abstract}

R. Kreiter - M. D. A. Rietkerk · H. M. van Veen .

J. F. Vente $(\bowtie)$

Energy Research Centre of the Netherlands, P.O. Box 1,

1755 ZG Petten, The Netherlands

e-mail: vente@ecn.nl

H. L. Castricum - J. E. ten Elshof

Inorganic Materials Science, MESA+ Institute for

Nanotechnology, University of Twente, P.O. Box 217,

7500 AE Enschede, The Netherlands

H. L. Castricum

Van 't Hoff Institute for Molecular Sciences, University of Amsterdam, Nieuwe Achtergracht 166, 1018 WV Amsterdam,

The Netherlands
Keywords Organic-inorganic hybrid - Membrane . Hydrothermal stability · Pervaporation · Gas separation . Microporous $\cdot \mathrm{HybSi}^{\circledR}$

\section{Introduction}

Industrial processes consume vast amounts of the world's total energy need. Calculations show that roughly one-third of this energy consumption is used in separation processes, among which the molecular separations are the most demanding [1]. Examples of these processes are purification of organic solvents, like the dewatering of bioalcohols, and gas separations, like the separation of hydrogen from a syngas mixture and the removal of sour components from natural gas. Membrane technology is generally accepted as a means to make industrial separation processes more energy efficient. Because of the demanding conditions of many industrial processes, e.g. high temperatures, pressures, or the presence of aggressive solvents, many research groups have focused on the development of ceramic membranes. The small nanopores $(<1 \mathrm{~nm})$ that are needed for molecular separations, make sol-gel thin films well-suited as membrane material. Silica-based materials have often been the material of choice, because of the low reactivity of silica precursors and because of the amorphous nature of the material formed. The low reactivity allows for a detailed investigation of particle and film formation, thereby enabling tuning of pore size and structure based on sol-gel parameters.

Unfortunately, the hydrothermal stability of inorganic silica is too low for industrial membrane applications [2]. As an example, inorganic silica membranes degrade within several days of operation in the dewatering of alcohols at industrially relevant temperatures of $70{ }^{\circ} \mathrm{C}$ and above. Several research groups have recognized this and have 
started looking for alternatives. Degradation of microporous silica membranes typically occurs via densification of the silica, followed by break up of the thin film. Densification of microporous materials in general is governed by a thermodynamic tendency towards lower surface areas and increased particle sizes. This implies that limiting the kinetics of the reactions that lead to densification is the only feasible option to prolong membrane life. In the case of silica-based materials this means that hydrolysis reactions and (surface) diffusion of fragments need to be slowed down or blocked. Depending on the exact mechanism of the densification, also the solubility of fragments can be reduced. One of the ways to achieve this is to incorporate organic side chains in the silica network, as in methylated silica (MeSi) $[2,3]$. It was proposed that a decreased water adsorption lowers the probability of siloxane hydrolysis in this material. Based on long-term dewatering measurements on this membrane material, the lifetime of MeSi proved to be much longer than that of inorganic silica. However, the application temperature of MeSi under these hydrothermal conditions is still limited to $95{ }^{\circ} \mathrm{C}$ [2]. At higher temperatures the membranes degraded within 20-40 days of operation. Duke et al. have demonstrated an elegant route for stabilization of silica by decomposing quaternary ammonium template molecules in the silica matrix [4]. The resulting carbon fragments inhibit the hydrolysis of silica to mobile silica fragments. The effect of this is a better steam stability of these carbonized-template molecular sieve silica (CTMSS) than of inorganic silica. This translates into a more stable $\mathrm{H}_{2} / \mathrm{CO}$ selectivity in gas separation experiments in the presence of steam. Clearly, the microporous structure is better retained in the CTMSS, whereas in inorganic silica the smallest pores close up in favor of larger pores.

An alternative method for stabilization of silica membranes described in literature is the introduction of metal ions in the silica matrix. Key examples of this approach are the silica-zirconia membranes [5, 6], that were applied in dewatering of organics, nickel-doped silica [7] and cobaltdoped silica $[8,9]$ that were tested for hydrogen permeance in the presence of steam. The metal doping enables a stable hydrogen permeance for at least several days in the presence of steam. A mechanism for this effect was proposed recently, based on observations of increased stability of niobium-doped silica [10]. This mechanism includes densification of part of the pore structure, while the overall microporosity is retained. It was suggested that $\mathrm{Nb}-\mathrm{O}-\mathrm{Si}$ bonds play a decisive role in the stabilization of this material. Still, the long-term effects on the densification of the silica pore structure have not been demonstrated.

For the successful industrial application of ceramic membranes in such applications, membrane life times of at least 2-3 years are required, putting the membrane replacement in line with regular maintenance intervals. To achieve this, we have chosen a different approach towards membranes with sufficient hydrothermal stability. We aimed to target the weakest link in the silica structure, the siloxane bond, and replace that at least partially by nonhydrolysable bonds. To this end, disilanes with organic bridges were selected as precursors, allowing for similar sol-gel chemistry as the previously developed for silica and MeSi membranes. Recently, we have demonstrated the exceptional stability of membranes based on mixtures of bridged and terminal organosilane precursors in pervaporation of water from alcohols [11-14]. These hybrid silica membranes $\left(\mathrm{HybSi}^{\circledR}\right)$ show very stable performance at temperatures as high as $150{ }^{\circ} \mathrm{C}$. The membranes have excellent water fluxes and selectivity and maintain this performance up to at least 600 days of total running time $[11,12]$. Subsequently, we introduced $\mathrm{HybSi}^{\circledR}$ membranes based on purely bridged precursors, which further improved the flux while retaining selectivity [13]. Moreover, these materials resist significant concentrations of inorganic $\left(\mathrm{HNO}_{3}\right)$ [13] and organic acids (acetic acid) [14]. This single precursor approach was later also applied for gas separation, showing a modest hydrogen over nitrogen selectivity of about $10[15,16]$. The hydrothermal stability of the hybrid silica membrane material was confirmed by these reports.

Our studies have indicated that the sols for such membranes should have an average hydrodynamic diameter around $5 \mathrm{~nm}[12,17]$ and fractal dimensions as obtained from SAXS of lower than 1.5 [12]. These data are in accordance with studies on inorganic silica sols for membrane preparation [18]. Consequently, strong particle interpenetration during drying and the formation of micropores are expected, leading to a highly interconnected organicinorganic network structure. Keeping in mind the targeted particle size and fractal dimension, we aimed to explore the sol-gel chemistry of hybrid silica sols based on bridged silane precursors. A detailed overview of the possible precursors and implications for mesoporous hybrid silica materials was presented before by Loy et al. [19]. They demonstrated that the size and nature of the bridging group can have a dramatic effect on mesoporous hybrid silica materials. To keep the pore structure as similar as possible to inorganic silica, we aimed for short organic bridging groups. Thus alkane-bridge precursors bis(triethoxysilyl)methane (BTESM), 1,2-bis(triethoxysilyl)ethane (BTESE), and 1,3-bis(triethoxysilyl)propane (BTESP) were selected for this study (Fig. 1). One rigid aromatic bridging group was also studied to monitor the reactivity of the sols under similar conditions. The benzene-bridged precursor 1,4-bis(triethoxysilyl)benzene (BTESB) was taken for this purpose.

Here we demonstrate a detailed study of the sol-gel chemistry of this small series of $\alpha, \omega$-bis(triethoxysilyl)alkane and -aromatic precursors and the implications on membrane performance. Our focus has been to explore small 


$$
\begin{array}{cc}
(\mathrm{EtO})_{3} \mathrm{Si} \frown \mathrm{Si}(\mathrm{OEt})_{3} & (\mathrm{EtO})_{3} \mathrm{Si} \\
\mathrm{BTESM} & \mathrm{Si}(\mathrm{OEt})_{3} \\
\text { BTESE } & \text { BTESB }
\end{array}
$$

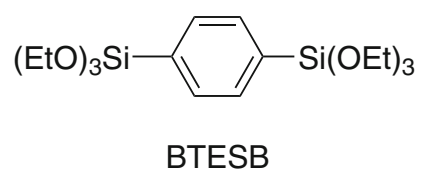

Fig. 1 Chemical structures of the applied precursors

nanoparticles $(1-10 \mathrm{~nm})$ with weak branching, to achieve pore size distributions in the lower microporous domain. Acid-catalyzed sol synthesis was selected, which in general promotes chain growth over branching. High-throughput screening (HTS) was used as synthesis tool to scan the parameter space of the sol synthesis parameters in detail. HTS allows for a rapid and accurate screening of many individual sol samples, from which suitable sols were selected for membrane preparations.

\section{Experimental}

\subsection{General}

The precursors BTESM, BTESE, BTESB, allyltriethoxysilane, and triethoxysilane were obtained from Gelest Inc. Karstedt's catalyst, platinum(0)divinyltetramethyldisiloxane, solution in vinylterminated poly(dimethylsiloxane) was obtained from Alfa Aesar. Ethanol AR quality was obtained from Biosolve B.V. All chemicals were used as received. BTESP was prepared by hydrosilylation of allyltriethoxysilane, as described below.

Automated sol syntheses were performed using a Chemspeed ASW1000 synthesis robot, equipped with a double thermostat bath to allow rapid temperature switches. Standard 16-position glass reactors were used. The samples were collected in glass vials and cooled to $-78{ }^{\circ} \mathrm{C}$ for storage. Prior to the DLS measurements sol samples were diluted with two parts of ethanol and filtered over a $0.45 \mu \mathrm{m}$ cellulose acetate filter. DLS measurements were performed on a Malvern Zetasizer Nano ZS. The hydrodynamic diameters were obtained from intensity plots against diameter. As a measure for the hydrodynamic diameter the average value of the peak was taken in the case of monomodal distributions, whereas in the less frequent cases of a bimodal distribution the average diameter of the most intense peak was used.

\subsection{Procedure for automated sol preparations}

All compounds were dissolved in ethanol in volumetric flasks prior to addition to the reactors. Stock solutions were prepared containing the respective precursors in concentrations of $0.78 \mathrm{M}$, water in $31.2 \mathrm{M}$, and $\mathrm{HNO}_{3}$ in $2.08 \mathrm{M}$ concentrations. While the reactors are cooled at $0{ }^{\circ} \mathrm{C}$, a variable volume of ethanol, a fixed amount of precursor solution $(5.0 \mathrm{~mL}, 3.9 \mathrm{mmol})$, a variable volume of $\mathrm{H}_{2} \mathrm{O}$ solution (max. $0.750 \mathrm{~mL}$ ), and a variable volume of $\mathrm{HNO}_{3}$ solution (max. $0.750 \mathrm{~mL}$ ) were added subsequently to give a total volume of $6.5 \mathrm{~mL}$. The temperature was then set at 40,60 , or $80^{\circ} \mathrm{C}$, respectively, and the mixture was kept at that temperature for $180 \mathrm{~min}$.

A total of 130 experiments were performed on a Chemspeed ASW1000 workstation divided over 9 runs. These experiments were randomized over the precursors and conditions leading to 32 experiments for BTESM, 34 for BTESE, 36 for BTESP, and 28 for BTESB covering 3 temperatures $\left(40,60\right.$, and $\left.80^{\circ} \mathrm{C}\right)$. These experiments were clustered per temperature and randomized over a matrix of 9 values of the ratio $\left[\mathrm{H}^{+}\right] /[\mathrm{Si}]$ versus 9 values of the ratio $\left[\mathrm{H}_{2} \mathrm{O}\right] /[\mathrm{OR}]$. In all automated runs one reference experiment was included. As reference experiment a mixture of methyltriethoxysilane (MTES) and tetraethyl orthosilicate (TEOS) was prepared in each run of 16 experiments, using a previously reported procedure [2]. While the reactor was cooled at $0{ }^{\circ} \mathrm{C}$, TEOS in ethanol $(1.651 \mathrm{~mL} ; 3.94 \mathrm{M}), \mathrm{H}_{2} \mathrm{O}$ in ethanol $(1.333 \mathrm{~mL} ; 31.2 \mathrm{M})$, and $\mathrm{HNO}_{3}(0.266 \mathrm{ml}$; $2.08 \mathrm{M}$ ) were added subsequently to give a total volume of $3.250 \mathrm{~mL}$. The temperature was then set to 40,60 , or $80^{\circ} \mathrm{C}$ and the mixture was kept at that temperature for $165 \mathrm{~min}$. MTES in ethanol $(3.250 \mathrm{~mL}, 2.0 \mathrm{M})$ was then added and reaction continued at the same temperature for $15 \mathrm{~min}$.

\subsection{Synthesis of 1,3-bis(triethoxysilyl)propane}

Neat allyltriethoxysilane $(77 \mathrm{~g}, \quad 0.37 \mathrm{~mol})$ was added dropwise to a solution of Karstedt's catalyst $(100 \mathrm{mg})$ in triethoxysilane $(64 \mathrm{~g}, 0.39 \mathrm{~mol})$ at $125^{\circ} \mathrm{C}$. After overnight stirring, the mixture was vacuum distilled to afford a first fraction of unreacted silanes and the pure disilane product (60 g, $160 \mathrm{mmol}, 43 \%)$ at $110{ }^{\circ} \mathrm{C} / 0.7 \mathrm{mbar}$. The amount of branched isomer (1,2-bis(triethoxysilyl)propane) in the product, was less than $10 \%$. Product purity was further confirmed by NMR: ${ }^{1} \mathrm{H}$ NMR $\left(\mathrm{CDCl}_{3}\right): \delta 3.84(\mathrm{q}, 12 \mathrm{H}$, $\left.\mathrm{OCH}_{2} \mathrm{CH}_{3}\right), 1.60$ (m, $\left.2 \mathrm{H}, \mathrm{SiCH}_{2} \mathrm{CH}_{2} \mathrm{CH}_{2} \mathrm{Si}\right), 1.22(\mathrm{t}, 18 \mathrm{H}$, $\left.\mathrm{OCH}_{2} \mathrm{CH}_{3}\right), 0.77\left(\mathrm{~m}, 4 \mathrm{H}, \mathrm{SiCH}_{2} \mathrm{CH}_{2} \mathrm{CH}_{2} \mathrm{Si}\right) .{ }^{13} \mathrm{C} \mathrm{NMR}$ $\left\{{ }^{1} \mathrm{H}\right\}\left(\mathrm{CDCl}_{3}\right): \delta 58.24,18.26,16.45,14.28$.

\subsection{Membrane preparation}

Supported mesoporous $\gamma$-alumina membranes were prepared by a dip-coating procedure of a boehmite sol on a $30 \mathrm{~cm}$ long tubular $\alpha$-alumina support system (ID/OD = $8 / 14 \mathrm{~mm}, 40 \mathrm{~cm}^{2}$, obtained commercially from TAMI) [20]. The freshly prepared hybrid sol was coated onto this 
$\gamma-\mathrm{Al}_{2} \mathrm{O}_{3}$ layer. Coating procedures were carried out under class 1000 clean room conditions to minimise defect formation due to dust particles. All layers were applied on the outside of the tubes. The supported and unsupported films were consolidated by a thermal treatment at $300{ }^{\circ} \mathrm{C}$ for $2 \mathrm{~h}$ in a nitrogen flow (99.999\% pure), applying heating and cooling rates of $0.5{ }^{\circ} \mathrm{C} / \mathrm{min}$.

\subsection{Membrane performance}

Pore size distributions of the hybrid silica layers were assessed by permporometry and calculated using the Kelvin equation [21, 22]. In these measurements helium was used as permeating gas and water as condensable gas. The total helium permeance in these measurements was in the range of $1-5^{*} 10^{-6} \mathrm{~mol} / \mathrm{m}^{2}$.Pa.s for all three membranes. Consecutive adsorption and desorption runs were identical.

Single gas permeance experiments were done with sequential permeation of $\mathrm{He}, \mathrm{N}_{2}, \mathrm{H}_{2}, \mathrm{CO}_{2}$, and $\mathrm{CH}_{4}$ using flows in the range of $1-1000 \mathrm{ml} / \mathrm{min}$ and pressures in the range of 2-8 bar. The pressure drop over the membrane was kept constant at 1 bar. Gas modules developed in-house were used in which the temperature inside the membrane is measured. The pre-heated gas is fed at the exterior of the membrane tube. To determine the permeance, permeate and retentate gas flows were measured at fixed pressures and calculated back to permeance using the effective membrane surface.

Pervaporation of water from alcohols was carried out using the supported membranes in a stirred vessel at a temperature of about $5-10{ }^{\circ} \mathrm{C}$ below the boiling point of the mixture (95/5 wt $\% \mathrm{ROH} /$ water, 1 bar). Water was continuously added with a pump to correct for the losses caused by the pervaporation process. The performance of the membranes was determined individually at regular intervals. The permeate sides of all membranes was kept at 10 mbar with a vacuum pump. The compositions of the feed and the permeate were determined by Karl Fischer titrations. The separation factor, $\alpha$, is defined as: $\alpha=\left(Y_{\mathrm{w}} / Y_{\mathrm{a}}\right) /\left(X_{\mathrm{w}} / X_{\mathrm{a}}\right)$, where $Y$ and $X$ are the weight fractions of water $(w)$ and alcohol $(a)$ in the permeate and feed solutions, respectively.

\section{Results}

\subsection{High-throughput synthesis}

For this study, a small series of linear $\alpha, \omega$-bistriethoxysilanes was selected, consisting of bistriethoxysilyl (BTES) methane (BTESM), BTES ethane (BTESE), and BTES propane (BTESP) (Fig. 1). In addition, the more rigid 1, 4-bistriethoxysilyl benzene (BTESB) was used. For each of these precursors sol syntheses were carried out using acidcatalyzed hydrolysis and condensation. The hydrolysis ratio, defined as the molar ratio of water and the ethoxygroups in the precursor $\left(\left[\mathrm{H}_{2} \mathrm{O}\right] /[\mathrm{OEt}]\right)$, was varied between 0.2 and 1 . The acid ratio $\left[\mathrm{H}^{+}\right] /[\mathrm{Si}]$, representing the molar ratio of $\mathrm{HNO}_{3}$ per silicon atom (two per precursor) was varied between 0.01 and 0.2 . The temperatures of the sol preparations were 40,60 , and $80{ }^{\circ} \mathrm{C}$, taking into account the boiling point of the mixture at around $80{ }^{\circ} \mathrm{C}$. Some of the experiments in this parameter space resulted in gel formation during synthesis, preventing a particle size determination. Typically, these samples were located at the higher acid and hydrolysis ratios. In particular in the cases when BTESB was used many samples rapidly gelled. Because of this, only a small number of results is shown for BTESB, that are biased to lower hydrolysis and acid ratios.

The results at the intermediate temperature of $60^{\circ} \mathrm{C}$ were considered first (Fig. 2). These plots clearly show that increased acid and water ratios both result in larger particle sizes for the alkane-bridged precursors. The precursors BTESM (Fig. 2a) and BTESE (Fig. 2b) lead to similar particle size distributions with a hydrodynamic diameter $\mathrm{d}$ in the range of $1.0-4.2 \mathrm{~nm}$ for BTESM and 1.1-3.8 for BTESE. These observations are consistent with our previous finding and with common observations for silica sol-gel chemistry. The graph for BTESP clearly shows smaller hydrodynamic diameters ranging from $0.8-2.4 \mathrm{~nm}$. This strong difference is not expected on the basis of differences in the electron density and therefore the reactivity of the silicon centre in this precursor. The results for the benzene-bridged precursor BTESB are strongly different from results for the linear alkane-bridged sols. Particle sizes of these sols are much higher, and many of the sol samples gelled before a particle size distribution could be measured.

The sol preparations at $80^{\circ} \mathrm{C}$ resulted in somewhat larger hydrodynamic diameters while at the lower temperature of $40{ }^{\circ} \mathrm{C}$ the values were lower. All four precursors follow the same trend. Because of the small differences between the three temperatures, only the largest diameters observed per temperature are presented (Table 1). Again, the diameters found for BTESM and BTESE are very similar, reflecting their similar reactivity and network forming ability. The maximum diameters for the BTESP sols were lower at all three temperatures with very similar values at 60 and $80{ }^{\circ} \mathrm{C}$. For BTESB much larger maximum diameters were found in all cases, indicating the higher reactivity of this precursor. Rapid gelation occurred for hydrodynamic diameters larger than $\sim 25 \mathrm{~nm}$. Particle size distributions of these gelled samples cannot be obtained and are not shown in the graph. Therefore, the apparent maximum diameters are close to the gel point and are not directly related to the differences in reactivity at the three temperatures for BTESB. 
Fig. 2 Hydrodynamic diameter against $\left[\mathrm{H}_{2} \mathrm{O}\right] /[\mathrm{OEt}]$ and $\left[\mathrm{H}^{+}\right] /$ [Si] for BTESM (a), BTESE (b), BTESP (c), and BTESB (d); Data points as well as their projections on the axes planes are shown
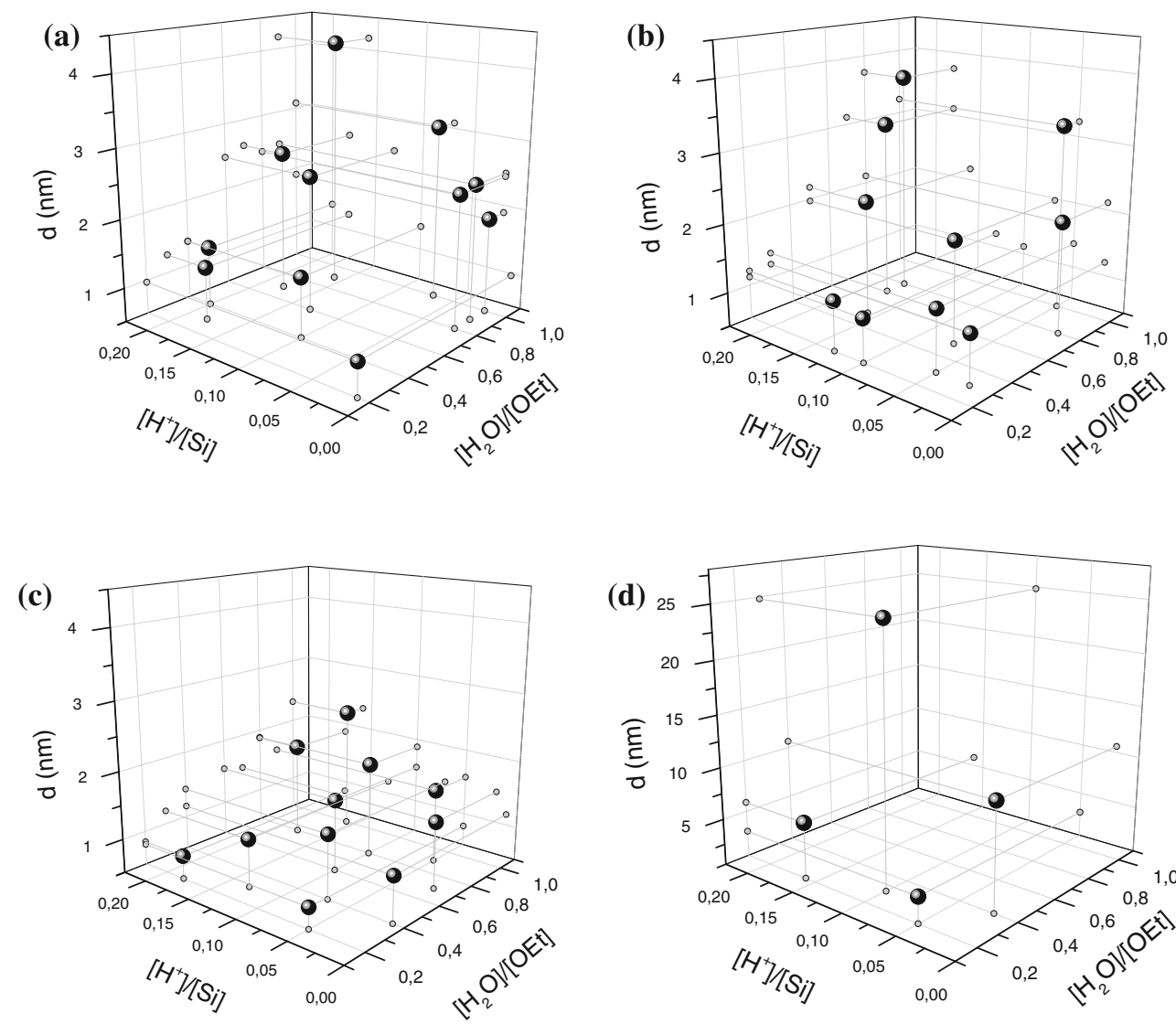

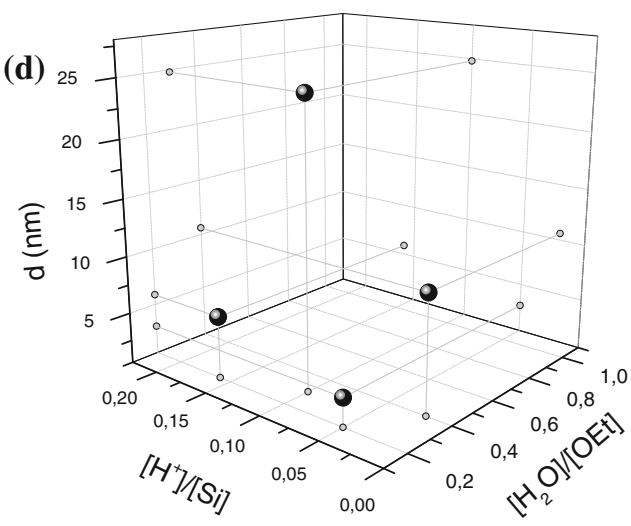

Table 1 Maximum hydrodynamic diameters (d) obtained for the different precursors at 40,60 , and $80{ }^{\circ} \mathrm{C}$

\begin{tabular}{lllll}
\hline T $\left({ }^{\circ} \mathrm{C}\right)$ & \multicolumn{4}{l}{ Maximum $d(\mathrm{~nm})$} \\
\cline { 2 - 5 } & BTESM & BTESE & BTESP & BTESB \\
\hline 40 & 3.8 & 2.6 & 1.8 & 20.0 \\
60 & 4.2 & 3.8 & 2.3 & 24.8 \\
80 & 6.9 & 6.4 & 2.4 & 26.5 \\
\hline
\end{tabular}

\subsection{Membrane preparation}

For the preparation of molecular sieve membranes, suitable sols were selected from the broad screening described above. Sols with particle sizes similar to the average pore size of the $\gamma$-alumina support $(4 \mathrm{~nm})$ were chosen, as these were the most promising for the preparation of these membranes. To this end, BTESM and BTESE in the sols with the composition ratios $\left[\mathrm{H}^{+}\right] /[\mathrm{Si}]=0.08$ and $\left[\mathrm{H}_{2} \mathrm{O}\right] /$ $[\mathrm{OEt}]=0.9$ were selected. The average particle sizes of all of the BTESP sols were assumed to be too small for coating on the mesoporous alumina support. Severe infiltration was expected, which leads to poor membrane quality [11]. The rapid gelation of the BTESB sols prevents practical application in membrane coatings, as a period of several hours is needed from sol preparation to coating a batch of membranes. In addition, it is unlikely that porous structures with small micropores can be prepared from these highly reactive sols. As a reference also membranes containing the precursors BTESE and MTES, containing a terminal methyl group, were prepared using previously reported procedures $[11,12]$.

The BTESM and BTESE sols were coated on tubular $\gamma$-alumina supports using previously described dip coating procedures $[12,13]$. The resulting membranes had layer thicknesses ranging from 200 to $600 \mathrm{~nm}$ (Fig. 3), depending on the specific coating conditions. SEM analysis showed that well-defined top layers were formed on the $\gamma$-alumina supports and that the membrane layers are smooth and defect free. The Kelvin pore size distribution analyses using permporometry show that the membranes based on BTESM and BTESE are microporous with average pore size diameters ranging from $0.5 \mathrm{~nm}$ for BTESM and $0.7 \mathrm{~nm}$ for BTESE (Fig. 4). Interestingly, the BTESE/MTES membrane prepared according to the previously reported procedure [11] has a smaller average pore size of $0.4 \mathrm{~nm}$. At the same time, the pore size distribution for this membrane is bimodal and has a relatively large contribution of pores larger than $1 \mathrm{~nm}$. The pore size distributions of the BTESM and BTESE membranes are monomodal and highly similar. 


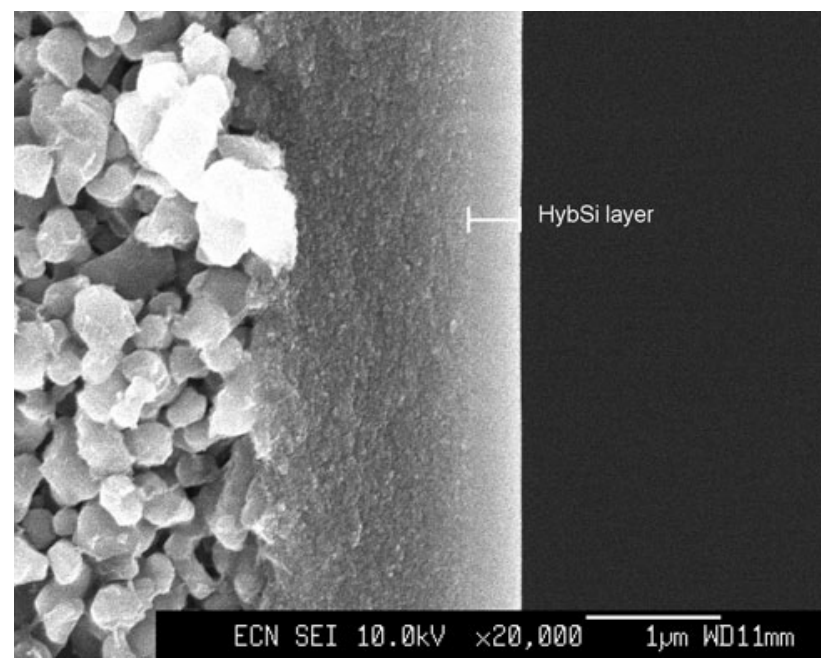

Fig. 3 SEM micrograph of the cross section of a BTESM membrane

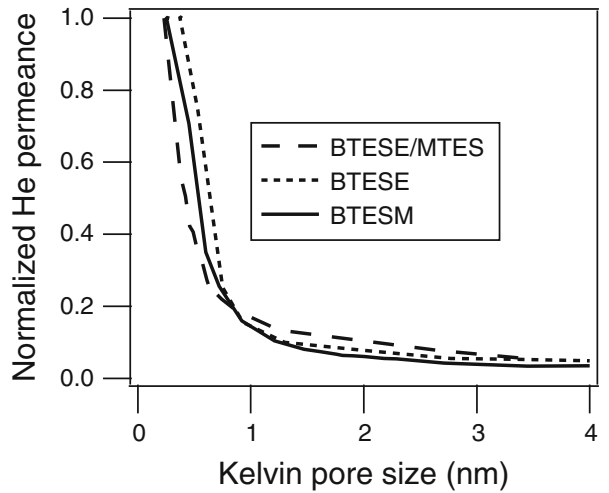

Fig. 4 Kelvin pore size distributions for BTESM, BTESE, and BTESE/MTES membranes

\subsection{Pervaporation performance}

Dehydration experiments of alcohol/water mixtures were performed using a series of lower alcohols. The separation performances of mixtures of $5 \mathrm{wt} \%$ water in methanol, ethanol, $n$-propanol, and $n$-butanol were determined. The water fluxes are highest in the most apolar alcohol (n-butanol) and decrease for the lower alcohols (Table 2). More importantly, the membranes show very different

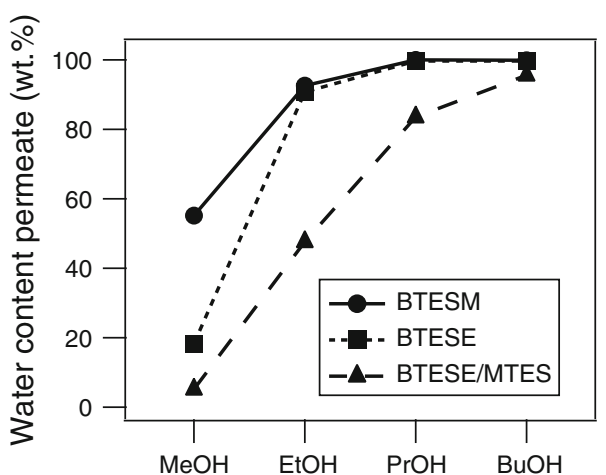

Fig. 5 Comparison of water content in the permeate against type of alcohol in the feed for BTESM, BTESE, and BTESE/MTES membranes

separation factors, depending on the specific mixture. Separation of water from $n$-butanol in all cases leads to a permeate purity of $>95 \%$ (Fig. 5). For this mixture, a separation factor $\alpha$ of over 400 is achieved for the BTESE/ MTES membrane and separation factors in the range of 4.000-10.000 are reached for BTESE and BTESM membranes. For the lower alcohols, the selectivity of the BTESE/MTES membrane is low. The single precursor membranes BTESE and BTESM have comparable performances for the dewatering of $n$-propanol and ethanol. The separation factor $\alpha$ obtained for the BTESM membrane in the dewatering of ethanol is over 200. For the dewatering of methanol, the BTESM membrane has a separation factor $\alpha$ of 23 , and performs much better than the BTESE membrane.

\subsection{Gas permeance selectivity}

Gas permeance results of the BTESM and BTESE membranes at $200{ }^{\circ} \mathrm{C}$ confirm that both membranes are microporous and have permeances for hydrogen of $2.4 \times 10^{-7}$ for BTESM and $1.1 \times 10^{-6}$ for BTESE. Both membrane types show a similar dependency of the permeance on the kinetic diameter (Fig. 6). Hydrogen permselectivity values were calculated from the single gas permeances and compared to values obtained for the BTESE/MTES membrane (Table 3). The BTESM and BTESE membranes both show

Table 2 Pervaporation performance of BTESE/MTES, BTESE, and BTESM membranes

\begin{tabular}{|c|c|c|c|c|c|c|c|}
\hline \multirow[t]{2}{*}{ Mixture $\left(\mathrm{H}_{2} \mathrm{O} / x\right)$} & \multirow[t]{2}{*}{$\mathrm{T}\left({ }^{\circ} \mathrm{C}\right)$} & \multicolumn{2}{|l|}{ BTESE/MTES } & \multicolumn{2}{|l|}{ BTESE } & \multicolumn{2}{|l|}{ BTESM } \\
\hline & & $J_{\mathrm{H}_{2} \mathrm{O}}\left(\mathrm{kg} \cdot \mathrm{m}^{-2} \mathrm{~h}^{-1}\right)$ & $\mathrm{Wt} \% \mathrm{H}_{2} \mathrm{O}$ & $J_{\mathrm{H}_{2} \mathrm{O}}\left(\mathrm{kg} \cdot \mathrm{m}^{-2} \mathrm{~h}^{-1}\right)$ & $\mathrm{Wt} \% \mathrm{H}_{2} \mathrm{O}$ & $J_{\mathrm{H}_{2} \mathrm{O}}\left(\mathrm{kg} \cdot \mathrm{m}^{-2} \mathrm{~h}^{-1}\right)$ & $\mathrm{Wt} \% \mathrm{H}_{2} \mathrm{O}$ \\
\hline$n-\mathrm{BuOH}$ & 95 & 3.69 & 95.8 & 2.33 & 99.6 & 3.98 & 99.8 \\
\hline$n-\mathrm{PrOH}$ & 85 & 2.73 & 83.5 & 1.76 & 99.5 & 2.82 & 99.5 \\
\hline $\mathrm{EtOH}$ & 70 & 1.28 & 42.0 & 0.73 & 89.2 & 1.18 & 92.2 \\
\hline $\mathrm{MeOH}$ & 55 & 0.30 & 4.6 & 0.27 & 18.6 & 0.60 & 55.1 \\
\hline
\end{tabular}

Water flux $\left(J_{\mathrm{H}_{2} \mathrm{O}}\right)$ and water content in the permeate shown for mixtures of lower alcohols and water $(95 / 5 \mathrm{wt} \%)$ 


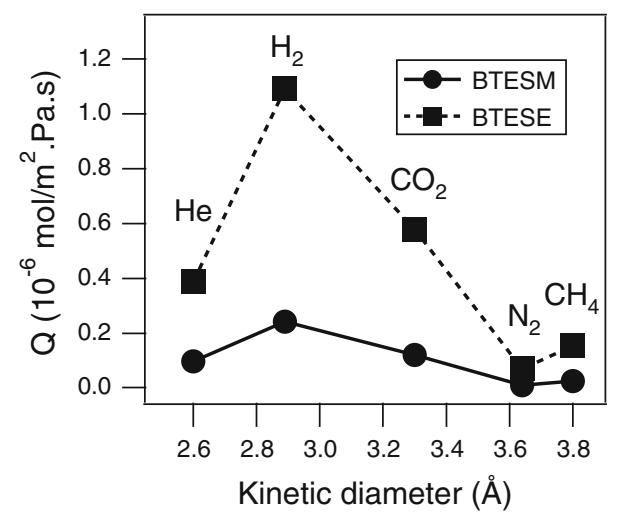

Fig. 6 Gas permeance (Q) of a series of gases against kinetic diameter for BTESM and BTESE membranes, measured at $200{ }^{\circ} \mathrm{C}$

Table 3 Permselectivity of $\mathrm{H}_{2}$ over other gases for BTESM, BTESE, and BTESE/MTES membranes at $200{ }^{\circ} \mathrm{C}$

\begin{tabular}{lccl}
\hline Gas pair & BTESM & BTESE & BTESE/MTES \\
\hline $\mathrm{H}_{2} / \mathrm{N}_{2}$ & 20.7 & 15.3 & 3.5 \\
$\mathrm{H}_{2} / \mathrm{CO}_{2}$ & 2.0 & 1.9 & 1.4 \\
$\mathrm{H}_{2} / \mathrm{CH}_{4}$ & 9.0 & 7.1 & 2.3 \\
\hline
\end{tabular}

modest $\mathrm{H}_{2} / \mathrm{N}_{2}$ permselectivity of 20.7 and 15.3 , respectively, whereas the BTESM/MTES membrane shows typical Knudsen selectivity. The BTESM membrane is somewhat more selective than the BTESE membrane, which is in line with the pervaporation results.

\section{Discussion and conclusions}

We have presented the rapid screening of a large number of sol samples using automated synthesis of hybrid silica sols and dynamic light scattering as the analytical tool. The successful selection of sols that allow membrane preparations shows that high-throughput screening of sols is a powerful tool for pre-selection sols in membrane development. It also allows for comparison of chemically similar precursors in a larger parameter space, as was shown for the three alkane-bridged precursors. The differences between BTESM and BTESE on the one hand and BTESP on the other were clearly identified. Moreover, this study shows that the particle size of these sols can be influenced with acceptable accuracy, by changing hydrolysis ratios and acid concentration.

The observed lower reactivity of BTESP is likely due to intramolecular cyclization during the condensation reactions. This is in line with a study by Loy et al., who showed that propane-bridged ethoxysilanes react to a six-membered intramolecular condensation product which further dimerizes to a bicyclic product [23]. Because of the much lower network forming ability of this product, the growth rate of the hybrid silica particles is slowed down. Probably, the formation of a six-membered ring is energetically more favorable than the five-membered ring that can be formed for BTESE, and the even more strained four-membered ring for BTESM. We believe that this is decisive for the apparent differences in reactivity between BTESP and the shorter BTESE and BTESM analogues. In our experiments this was observed as a reduced maximum particle size for BTESP, compared to BTESM and BTESE. Because of the confirmation of the purity of the precursor by NMR, the possibility of ring forming before the sol-gel synthesis can be ruled out. In BTESP, the two silicon centers are ideally positioned for ring formation, mainly because of the favorable distance and bond angles. Longer bridged precursors would presumably have a lower probability of intramolecular ring formation, because of the lower frequency of a favorable encounter of the reactive groups. Presumably, suitable hydrodynamic diameters are more easily obtained for alkane-bridged precursors longer than BTESP.

In contrast, BTESB does not have the possibility for intramolecular condensation reactions. The observed larger particle sizes are in line with the lower electron density of the silicon atoms in BTESB compared to the alkanebridged precursors. This is an effect of the electron withdrawing properties of the benzene fragment, compared to the weakly electron donating properties of alkyl fragments. Because of this the reactivity in the nucleophilic substitution reactions involved in hydrolysis of alkoxysilanes increases. Consequently, the observed reactivity and particle growth rate of BTESB are much higher than the alkane-bridged precursors. Gelation was frequently observed within the parameter range that was currently studied. Therefore, we conclude that the BTESB sols that were currently studied are not suitable for membrane preparations

The membranes prepared from BTESM and BTESE clearly have narrower pore distribution than membranes based on BTESE/MTES mixtures. This can be attributed to the bimodal pore size observed for the MTES-containing membranes. Possibly, a non-homogeneous distribution of MTES throughout the final hybrid silica network is the reason for the larger pores. Interestingly, the BTESM membrane has a lower average pore size than the BTESE membrane. At apparent pore sizes in the range of $\sim 0.5 \mathrm{~nm}$, ring structures composed of 2-4 precursor units dominate the transport pathway. We therefore propose that the smaller minimal size of the ring structures of the methane-bridged compared to the ethane-bridged network is the direct cause of this smaller average pore size.

The pore size differences of these $\mathrm{HybSi}^{\circledR}$ membranes are also reflected in large differences in the selectivity in 
pervaporation. The separation factor of the BTESE/MTES membrane probably suffers from the relatively large contribution of pores $>1 \mathrm{~nm}$, despite the fact that its average pore size is the lowest of the three membrane types. Similar observations of bimodal pore size distributions caused by MTES were made in adsorption studies on methylated silica gels [24]. For the purely bridged precursor membranes even the comparatively small difference between BTESM and BTESE membranes leads to a dramatic difference in selectivity for $\mathrm{MeOH} / \mathrm{H}_{2} \mathrm{O}$ mixtures. The flux differences between the different alcohol/water mixtures are due to differences in feed temperature and activity of water in the respective mixtures. Similar trends for pervaporation of a series of water/alcohol mixtures were reported by Sommer et al. [25].

The $\mathrm{H}_{2} / \mathrm{N}_{2}$ permselectivity results are in line with the permporometry and pervaporation results, showing a slightly higher selectivity for the shorter organic bridge. The values of the obtained $\mathrm{H}_{2} / \mathrm{N}_{2}$ selectivity are similar to those reported by Tsuru et al. for BTESE-based membranes [15], and are at least an order of magnitude lower than those reported for inorganic silica [3]. The consistency between these two independent studies can be taken as an indication that the current approach leads to an intrinsic average pore size of the hybrid silica network which results in limited hydrogen permselectivity. We anticipate that different approaches outside the commonly studied reaction parameters are needed to improve the selectivity to values that are interesting for practical applications.

In conclusion, we have demonstrated that large numbers of organic-inorganic hybrid silica sols can be prepared and screened, allowing tailoring of sol structures towards expected membrane performance. The difference in behavior for $\mathrm{HybSi}^{\circledR}$ membranes based on three precursor types shows that small differences in precursor structure allow for significantly different membrane properties. In all of these membranes, the bridged silane motif is present, which is believed to be essential for the hydrothermal stability of these membranes. Future research focuses on the application of specific precursors or precursor mixtures for dedicated membrane behavior.

Acknowledgments Dr. J.B.M. Wilting and Dr. H.C.L. Abbenhuis of Hybrid Catalysis, Eindhoven the Netherlands are kindly acknowledged for the automated high-throughput experiments.
Open Access This article is distributed under the terms of the Creative Commons Attribution Noncommercial License which permits any noncommercial use, distribution, and reproduction in any medium, provided the original author(s) and source are credited.

\section{References}

1. Vente JF, van Veen HM, Pex PPAC (2007) Ann Chim Sci Mat 32:231

2. Campaniello J, Engelen CWR, Haije WG, Pex PPAC, Vente JF (2004) Chem Commun 834

3. de Vos RM, Verweij H (1998) Science 279:1710

4. Duke MC, Diniz da Costa JC, Do DD, Gray PG, Lu GQ (2006) Adv Funct Mater 16:1215

5. Asaeda M, Ishida M, Tasaka Y (2006) Separ Sci Techn 40:239

6. Asaeda M, Sakou Y, Yang J, Shimasaki K (2002) J Membr Sci 209:163

7. Kanezashi M, Asaeda M (2006) J Membr Sci 271:86

8. Battersby S, Smart S, Ladewig B, Liu S, Duke MC, Rudolph V, da Costa JCD (2009) Separ Purif Techn 66:299

9. Igi R, Yoshioka T, Ikuhara YH, Iwamoto Y, Tsuru T (2008) J Am Ceram Soc 91:2975

10. Boffa V, Blank DHA, ten Elshof JE (2008) J Membr Sci 319:256

11. Castricum HL, Sah A, Kreiter R, Blank DHA, Vente JF, ten Elshof JE (2008) Chem Commun 1103

12. Castricum HL, Sah A, Kreiter R, Blank DHA, Vente JF, Ten Elshof JE (2008) J Mater Chem 18:1

13. Castricum HL, Kreiter R, van Veen HM, Blank DHA, Vente JF, ten Elshof JE (2008) J Membr Sci 324:111

14. Kreiter R, Rietkerk MDA, Castricum HL, van Veen HM, Ten Elshof JE, Vente JF (2009) ChemSusChem 2:158

15. Kanezashi M, Yada K, Yoshioka T, Tsuru T (2009) J Am Chem Soc 131:414

16. Kanezashi M, Yada K, Yoshioka T, Tsuru T (2010) J Membr Sci 248

17. Castricum HL, Sah A, Geenevasen J, Kreiter R, Blank DHA, Vente JF, ten Elshof JE (2008) J Sol-Gel Sci Techn 48:11

18. Elferink WJ, Nair BN, de Vos RM, Keizer K, Verweij H (1996) J Colloid Interface Sci 180:127

19. Shea KJ, Loy DA (2001) Chem Mater 13:3306

20. Bonekamp BC (1996) Preparation of Asymmetric Ceramic Membrane Supports by Dip-Coating. In: Burggraaf AJ, Cot L (Eds) Fundamentals of Inorganic Membrane Science and Technology. Elsevier, Amsterdam, Ch. 6, p. 141

21. Deckman HW, Chance RR, Cox DM, de Gijnst WG, Reinoso JJ (13-9-2003) United States patent US 2003/0005750

22. Tsuru T, Hino T, Yoshioka T, Asaeda M (2001) J Membr Sci 186:257

23. Loy DA, Carpenter JP, Alam TM, Shaltout R, Dorhout PK, Greaves J, Small JH, Shea KJ (1999) J Am Chem Soc 121:5413

24. Castricum HL, Sah A, Mittelmeijer-Hazeleger MC, Huiskes C, ten Elshof JE (2007) J Mater Chem 17:1509

25. Sommer S, Melin T (2005) Chem Eng Sci 60:4509 